\title{
Platelet-rich Plasma Modulates the Secretion of Inflammatory/ Angiogenic Proteins by Inflamed Tenocytes
}

\author{
Isabel Andia PhD, Eva Rubio-Azpeitia MSc, \\ Nicola Maffulli MD, MS, PhD, FRCS (Orth)
}

Published online: 11 February 2015

(C) The Association of Bone and Joint Surgeons (B) 2015

\begin{abstract}
Background Platelet-rich plasma therapies for tendinopathy appear to provide moderate pain reduction. However, the biological mechanisms behind the observed clinical effects remain poorly characterized.

Questions/purposes The purpose of this study was to explore whether platelet-rich plasma modifies the inflammatory/angiogenic status of already inflamed tenocytes by
\end{abstract}

The Department of Industry from the Basque Government provided financial support, SAIO2012-PE12BF007.

All ICMJE Conflict of Interest Forms for authors and Clinical Orthopaedics and Related Research ${ }^{\mathbb{R}}$ editors and board members are on file with the publication and can be viewed on request.

Clinical Orthopaedics and Related Research ${ }^{\mathbb{R}}$ neither advocates nor endorses the use of any treatment, drug, or device. Readers are encouraged to always seek additional information, including FDAapproval status, of any drug or device prior to clinical use.

Each author certifies that his or her institution approved the human protocol for this investigation, that all investigations were conducted in conformity with ethical principles of research, and that informed consent for participation in the study was obtained.

This work was performed at BioCruces Health Research Institute, Cruces University Hospital, Barakaldo, Spain.

I. Andia, E. Rubio-Azpeitia

Regenerative medicine Group, Biocruces Health Research

Institute, Cruces University Hospital, 48903 Barakaldo, Spain

N. Maffulli

Department of Musculoskeletal Disorders, University of Salerno

School of Medicine and Surgery, Salerno, Italy

N. Maffulli ( $\square)$

Barts and the London School of Medicine and Dentistry, Centre for Sports and Exercise Medicine, Mile End Hospital, Queen Mary University of London, 275 Bancroft Road, London E1 4DG, UK

e-mail:n.maffulli@qmul.ac.uk examining (1) gene expression; (2) modulation of chemokine and interleukin secretion; and (3) differences between healthy and tendinopathic tenocytes.

Methods Cells from both healthy and tendinopathic tendons were exposed to interleukin (IL)- $1 \beta$ and after treated with platelet-rich plasma. Modifications in the expression of selected genes were assessed by real-time reverse transcription-polymerase chain reaction and changes in secretion of angiogenic/inflammatory molecules by enzyme-linked immunosorbent assay. Platelet-rich plasmainduced changes in tendinopathic cells were compared with normal after normalizing platelet-rich plasma data against IL-1ß status in each specific sample.

Results In IL-1ß-exposed cells, platelet-rich plasma downregulates expression of IL-6/CXCL-6 (mean, 0.015; 95\% confidence interval $[\mathrm{CI}], 0.005-0.025 ; \mathrm{p}=0.026$ ), IL-6R (mean, 0.61; 95\% CI, 0.27-0.95; $\mathrm{p}=0.029$ ), and IL-8/CXCL-8 (mean, 0.02; 95\% CI, 0.007-0.023; $\mathrm{p}=0.026$ ). Secretion of IL-6/CXCL6, 0.35 (95\% CI, 0.3$0.4 ; \mathrm{p}=0.002), \mathrm{IL}-8 / \mathrm{CXCL} 8,0.55$ (95\% CI, 0.5-0.7; $\mathrm{p}=0.01$ ), and monocyte chemoattractant protein-1/CCL2, 0.40 (95\% CI, $0.2-0.6 ; \mathrm{p}=0.001)$ was reduced by platelet-rich plasma, whereas vascular endothelial growth factor increased by twofold, (95\% CI, 1.7-2.3; p < 0.001). RANTES/CCL5 increased by 10 -fold (95\% CI, 4-17) and hepatocyte growth factor by 21 -fold $(95 \%$ CI, 0.2-42) in tendinopathic and by 2.3 -fold $(95 \% \mathrm{CI}, 2-3)$ and threefold (95\% CI, 1-5) in normal cells ( $\mathrm{p}=0.005$ for both).

Conclusions Platelet-rich plasma induces an immunomodulatory and proangiogenic phenotype consistent with healing mechanisms with few differences between tendinopathic and normal cells.

Clinical Relevance Platelet-rich plasma injections in pathological and nearby tissue might help to recover tendon homeostasis. 


\section{Introduction}

Platelet-rich plasma therapies are among current biologic interventions used to ameliorate medical conditions that necessitate tissue healing [4]. The multimolecular preparations, obtained from autologous blood, provide clinical benefits by modulating the early healing response through secretion of an array of signaling cytokines that influence inflammation and angiogenesis concurrently and influence cell migration and proliferation [10, 13, 23, 24]. Plateletrich plasma affects healing, both physiologically and pathologically, and is currently used not only in surgery [2, 16], but also as an injectable to treat pathological conditions such as osteoarthritis (OA) and tendinopathies $[5,6$, 14], in which the disordered vascularization and deleterious neoinnervation are associated with reduced healing capability and increased vulnerability to chronic injuries.

Although there is preliminary evidence of clinical efficacy of platelet-rich plasma (PRP), this is controversial, and how PRP might influence the inflammatory and angiogenic status of already inflamed tenocytes is not well understood. Examining the expression of selected genes and evaluating the synthesis of chemokines and interleukins that are upregulated in inflamed tendons might provide a window into this issue. Inflammation and angiogenesis are necessary steps for healing; however, unbalanced angiogenesis/inflammation as a consequence of deregulation of the cytokine (chemokine) network can result in a chronic pathological environment that leads to impaired healing [28], often clinically manifested as pain. Prototypical inflammatory mediators such as interleukin (IL)-1B, monocyte chemoattractant protein (MCP)-1/ CCL2, IL-8/CXCL8, and IL-6/CXCL6 have been shown to induce acute or short-term hyperalgesia and are implicated directly in neuropathic pain, chronic hyperalgesia, and allodynia [37, 39, 40].

Because PRP is used in areas where there is both normal and pathological tissue, evaluating its effects on both seems important, but we really do not have a full picture about how the secretion of inflammatory/angiogenic proteins in response to PRP may differ in normal versus inflamed tendon. Accumulating data demonstrate the participation of multiple cytokines in tendon conditions, from acute traumatic rupture to chronic tendinopathy. Indeed, the lack of specific cytokines may impair tissue regeneration as shown in IL-6 knockout mice [22]. Novel findings show that the most dramatic effect during tendon repair is an exceptionally high upregulation in the expression of IL- $1 \mathrm{~b}$ (greater than 4000-fold) [26]. In addition, chemokines (MCP-1/C-C motif ligand [CCL]2, regulated on activation, normal $\mathrm{T}$ expressed and secreted [RANTES]/CCL5) that modulate the migration of immune cells are involved in the early phases of healing after experimental section of the
Achilles tendon in an animal model [36]. These chemokines participate not only in inflammation and pain modulation, but also in angiogenesis. Understanding their mechanisms of action will allow us to extend previous knowledge reporting on MCP-1/CCL2, RANTES/CCL5, vascular endothelial growth factor (VEGF), and hepatocyte growth factor (HGF) production by tendon cells after PRP treatment $[11,12]$.

The purposes of our study were to (1) explore whether PRP could modify the inflammatory and angiogenic status of already inflamed tenocytes by examining the expression of selected genes relevant to tendon biology; (2) examine the extent to which PRP can modulate the secretion of chemokines and interleukins that are upregulated in inflamed tendons; and (3) determine whether the secretion of inflammatory/angiogenic proteins in response to PRP are different between healthy and tendinopathic cells.

\section{Materials and Methods}

Tissue fragments that would otherwise have been discarded after surgery were collected from semitendinosus tendon samples obtained during surgical reconstruction of the anterior cruciate ligament (these specimens were used as sources of healthy tenocytes) and fragments obtained after débriding frayed portions of the rotator cuff tendons (which were used to provide tendinopathic tendon cells). Samples were obtained after receiving informed consent from patients and local ethics committee approval. Tendon cells were isolated by an explant procedure and cultured as previously described [9]. All the experiments were performed in cells at passages between two and three, ie, to avoid dedifferentiation no more than three times the cells in the culture have been split and subcultured.

Peripheral blood was collected in 9-mL tubes containing sodium citrate as anticoagulant (Vacuette; Greiner BioOne, Kremsmünster, Austria). Tubes were centrifuged at $600 \mathrm{G}$ for 6 minutes, and the plasma layer was collected avoiding aspiration of the buffy coat. Platelets and leukocytes in PRP were counted using a Coulter Counter (Beckman, Brea, CA, USA). This PRP is the same as we use in our clinical studies [27] and is pure PRP (no leukocytes) with a moderated enrichment of platelets $(2.30 \pm 0.68$ times greater than peripheral blood baseline). For cell cultures, platelet activation was performed by three freeze-thaw cycles, then filtered through $0.22-\mu \mathrm{m}$ filters, and stored frozen at $-20{ }^{\circ} \mathrm{C}$. In contrast to thrombin $/ \mathrm{CaCl}_{2}$ activation, which yields to the soluble protein fraction, the so-called releasate or supernatant, the product resulting from freezethawed procedures includes fibrinogen.

To match cells and PRP according to tendinopathic status, healthy tendon cells from two donors were treated 
with allogeneic PRP from four healthy donors in individual experiments performed in triplicate. Similarly, cells isolated from tendinopathic tissues (rotator cuff tendons) were treated with PRP from four patients with lateral elbow epicondylopathy participating in a randomized blind trial [27]. All donors gave their informed consent. Cells were seeded in six-well plates at a density of 4000 cells $/ \mathrm{cm}^{2}$ and were grown until subconfluence was reached (10,000 cells/ $\mathrm{cm}^{2}$ ). After reaching subconfluence, cells were starved for 30 hours to arrest the cell cycle and to start the experiment with all cells at the same baseline. Cells were then treated for 48 hours with $1 \mathrm{ng} / \mathrm{mL}$ recombinant IL-1ß (Sigma Aldrich, St Louis, MO, USA). At that point, culture medium containing IL-1ß and the newly released proteins were removed, and fresh culture medium supplemented with $10 \%$ PRP was added.

Both the tendon cells and cell culture supernatants were harvested in three different situations: (1) after starvation (constitutive secretion); (2) some cells were starved and harvested after 48 hour exposure to IL-1ß (inflamed cells); and (3) other cells received both IL-1ß (for 48 hours) and an additional 72-hour PRP exposure (PRP-treated cells) (Fig. 1).

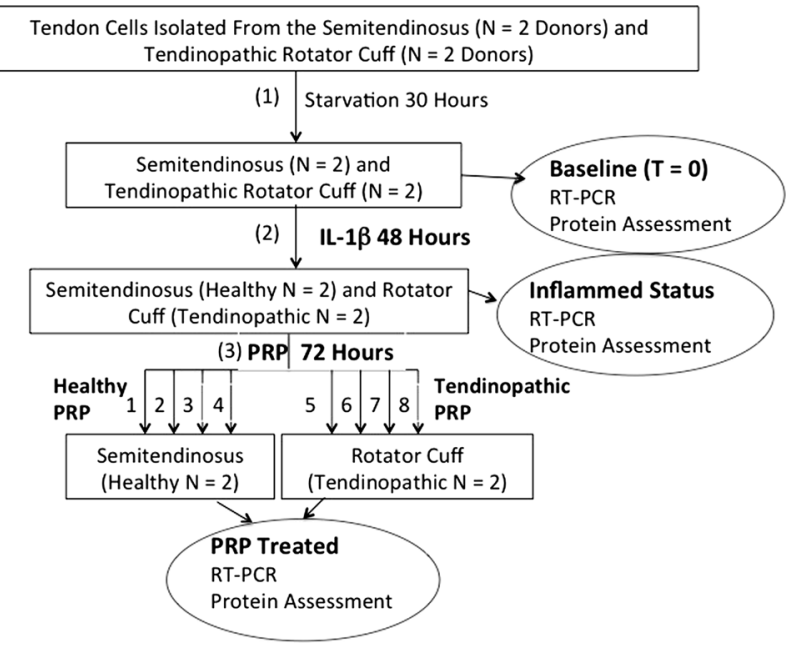

Fig. 1 Experimental design: after cell-cycle synchronization (30 hours using $0.2 \%$ PRP), starved cells ( $t=0$ hours) were treated with $1 \mathrm{ng} / \mathrm{mL}$ rh-IL-1ß for 2 days and then exposed to 10\% PRP for the next 3 days. Experiments were performed in parallel with healthy tendon cells from the semitendinosus tendon $(\mathrm{N}=2$ donors $)$ and tendinopathic tendon cells from the rotator cuff ( $\mathrm{N}=2$ donors). PRPs were prepared from four healthy donors and used to treat healthy cells and from four patients with tendinopathy and used to treat tendinopathic cells. Both the tendon cells and cell culture supernatants were harvested in three different situations: (1) after starvation (constitutive secretion); (2) some cells were starved and harvested after 48-hour exposure to IL-1ß (inflamed cells); and (3) other cells received both IL-1 (for 48 hours) and an additional 72-hour PRP exposure (PRPtreated cells). RT-PCR $=$ reverse transcription-polymerase chain reaction.
Total RNA was isolated using the High Pure RNA Isolation Kit (Roche, Basel, Switzerland) according to the manufacturer's instructions. RNA was quantified and quality assessed using the NanoDrop 2000 (Thermo Scientific, Waltham, MA, USA). Using random hexamers, $1 \mu \mathrm{g}$ RNA was reverse-transcribed to cDNA in $20 \mu \mathrm{L}$ (SuperScript $^{\circledR}$ III First-Strand Synthesis System; Invitrogen Life Technologies, Carlsbad, CA, USA). For the realtime polymerase chain reaction (PCR), the cDNA from each sample was diluted fivefold, and $2 \mu \mathrm{L}$ of cDNA (20 ng) was mixed with Power SYBR ${ }^{\circledR}$ Green PCR Master Mix (Applied Biosystems, Life Technologies) and 5 pmoles of primers for a $20-\mu \mathrm{L}$ final volume. Real-time PCR reactions were performed on the ABI-7900 (Applied Biosystems, Life Technologies). The PCR reactions were performed in triplicate for each sample.

One microgram of cDNA was amplified in a $20-\mu \mathrm{L}$ reaction mixture containing primers for inflammatory factors, including IL-1ß, IL-1ß receptor, IL-6 receptor, IL-6, IL-8, transforming growth factor (TGF)-B1, cyclooxygenase (COX)-1, COX-2, and ECM molecules, including Col1, $\mathrm{Col} 3$, a disintegrin, and metalloproteinase with thrombospondin motifs (ADAMTS4, ADAMTS5, matrix metallopeptidase (MMP)-1, MMP-3, tissue inhibitors of metalloproteinase (TIMP)-1, and hyaluronan synthase 2 (HAS2). Glyceraldehyde 3-phosphate dehydrogenase (GAPDH) and TATA-binding protein (TBP) were amplified as reference housekeeping genes (Table 1). We normalized data against the mean of two housekeeping genes with variable ranges of expression (GAPDH, high expression, and TBP, moderately low) to increase precision Data were first normalized to the mean of GAPDH and TBP and then again to the IL-1ß group by means of the $2^{-\Delta \Delta \mathrm{Ct}}$ method [21] where $\mathrm{Ct}=$ cycle threshold.

Secreted proteins by tendon cells, in the different experimental conditions (constitutive, inflamed, and PRPtreated) were assessed using solid-phase sandwich enzymelinked immunoabsorbent assays (ELISAs) and solid-phase enzyme-amplified sensitivity immunoassays (EASIA). ELISA procedures were used to quantify hepatocyte growth factor (R\&D Systems Inc, Minneapolis, MN, USA), VEGF (-165) (Invitrogen Corporation, Caramillo, CA, USA), GRO-alpha/CXCL1, and MCP-1/CCL2 (RayBiotech Inc, Norcross, GA, USA). EASIA procedures were used to quantify RANTES/CCL5, IL-6/CXCL6, and IL-8/ CXCL8 (Biosource Europe SA, Nivelles, Belgium). All kits were used according to the manufacturer's instructions. The contribution of PRP proteins to the total was subtracted, and the concentration of proteins secreted by cells was expressed as ng/10 6 cells, as previously described [7]. Viable cell number was assessed in a Burker Chamber using Trypan Blue (Sigma-Aldrich, St Louis MO, USA); the procedure was performed in duplicate. 
Table 1. Polymerase chain reaction primers used in this study

\begin{tabular}{llll}
\hline Primer & Forward $\left(5^{\prime}-3^{\prime}\right)$ & Reverse $\left(5^{\prime}-3^{\prime}\right)$ & Annealing temperature $\left({ }^{\circ}\right.$ C $)$ \\
\hline IL-1 $\beta$ & TCCAGGGACAGGATATGGAGCA & AGGCCCAAGGCCACAGGTATTT & 58 \\
IL-1 $\beta$ R & GGTGACAGTAACTGGTGTT & ACGTTGGGGAAGACATTGTT & 52 \\
IL-6 & GAGGCACTGGCAGAAAACAACC & CCTCAAACTCCAAAAGACCAGTGATG & 58 \\
IL-6R & AAGACCCCCACTCCTGGAACT & CGTGGATGACACAGTGATGCT & 60 \\
IL-8 & CTGTCTGGACCCCAAGGAAAACT & GCAACCCTACAACAGACCCACAC & 57 \\
TGF- $\beta$ & GAGGTCACCCGCGTGCTAATG & CACGGGTTCAGGTACCGCTTCT & 58 \\
COX-1 & GGTTTGGCATGAAACCCTACACCT & CCTCCAACTCTGCTGCCATCT & 58 \\
COX-2 & AACTGCGCCTTTTCAAGGATGG & TGCTCAGGGACTTGAGGAGGGT & 58 \\
COL1A1 & GGCAACAGCCGCTTCACCTAC & GCGGGAGGACTTGGTGGTTT & 58 \\
COL3A1 & CACGGAAACACTGGTGGACAGATT & ATGCCAGCTGCACATCAAGGAC & 58 \\
HAS-2 & GTCCCGGTGAGACAGATGAG & ATGAGGCTGGGTCAAGCATAG & 58 \\
ADAMTS4 & GACACTGGTGGTGGCAGATG & TCACTGTTAGCAGGTAGCGCTTTA & 52 \\
ADAMTS5 & ATGAGGAGCACTACGATGCAGCTA & CTGTGATGGTGGCTGAAGTGCAT & 60 \\
MMP-1 & CAACTCTGGAGTAATGTCACA & TACATCAAAGCCCCGATATCA & 58 \\
MMP-3 & TTTTGGCCATCTCTTCCTTCA & TGTGGATGCCTCTTGGGTATC & 55 \\
TIMP-1 & GGCCTTAGGGGATGCCG & CGGCTATCTGGGACCGCA & 52 \\
GAPDH & GCATTGCCCTCAACGACCACT & CCATGAGGTCCACCACCCTGT & \\
TBP & TGCACAGGAGCCAAGAGTGAA & CACATCACAGCTCCCCACCA & 58 \\
\end{tabular}

IL-1 $\beta=$ interleukin 1 beta; IL-1 $\beta \mathrm{R}=$ interleukin 1 beta receptor; IL-6 = interleukin 6; IL-6R = interleukin 6 receptor; IL-8 = interleukin 8; TGF- $\beta=$ transforming growth factor beta 1 COX-1 and COX- $2=$ cytochrome $\mathrm{c}$ oxidase subunit 1 and subunit 2 ; COL $1 \mathrm{~A} 1=$ collagen type 1 alpha $1 ;$ COL $3 \mathrm{~A} 1=$ collagen type 3 alpha 1 ; HAS-2 = hyaluronan synthase 2; ADAMTS4 and ADAMTS5 = ADAM metallopeptidase with thrombospondin type 1 motif, 4 and motif, 5; MMP-1 = matrix metallopeptidase 1 (interstitial collagenase); MMP-3 = matrix metallopeptidase 3 (stromelysin 1, progelatinase); TIMP-1 = TIMP metallopeptidase inhibitor 1; GAPDH = glyceraldehyde-3-phosphate dehydrogenase; $\mathrm{TBP}=$ TATA box binding protein

Sulfated proteoglycan and glycosaminoglycan content was determined in cell supernatants Blyscan ${ }^{\mathrm{TM}}$ Glycosaminoglycan Assay (Biocolor, Carrickfergus, Northern Ireland, UK) according to the manufacturer's instructions with the suitable dilutions.

The experiments were performed in triplicate for each of the eight PRP donors. The relative gene expression (referred to IL-1ß) and the concentration of proteins were shown as median and 25th to 75th percentiles. Data of protein secretion after PRP were normalized against IL-1B for each cell donor. The Spearman rank correlation test was used to describe associations. The $\mathrm{p}$ values were determined using the Kruskal-Wallis test and the MannWhitney $U$ test for nonparametric independent data. A p value of $<0.05$ was considered significant. Data were analyzed using SPSS for Windows, Version 18.0 (SPSS; IBM, Armonk, NY, USA).

\section{Results}

PRP could appear to mitigate the inflammatory and angiogenic status of already inflamed tenocytes because its application downregulates gene expression of inflammatory interleukins, specific receptors, and other molecules (Fig. 2A-D). In inflamed tendon cells (IL-1 $\beta$ exposed; Table 2), PRP downregulates gene expression of IL-1ß (mean, 0.1; 95\% confidence interval [CI], -0.05 to $0.25 ; \mathrm{p}=0.029$ ), IL-6/CXCL-6 (mean, $0.015 ; 95 \% \mathrm{CI}$, $0.005-0.025 ; \mathrm{p}=0.026$ ), IL-6R (mean, $0.61 ; 95 \% \mathrm{CI}$, $0.27-0.91 ; \mathrm{p}=0.029$ ), and IL-8/CXCL-8 (mean, 0.57; $95 \% \mathrm{CI},-0.3$ to $1.45 ; \mathrm{p}=0.029)$ as well as COX-2 (mean, 0.06; 95\% CI, 0.01-0.13; $\mathrm{p}=0.005$ ). PRP had no effect on IL-1R1 (mean, 1.8; 95\% CI, 1-2.5; p = 0.576), TGF-B1 (mean, $1.23 ; 95 \%$ CI, $0.3-2 ; \mathrm{p}=1.0$ ), ADAMTS4 (mean, 1.6; 95\% CI, 0.5-2.7; $\mathrm{p}=1.0$ ), and HAS2 (mean, $0.5 ; 95 \% \mathrm{CI}, 0.3-0.8 ; \mathrm{p}<0.282)$ in our experimental conditions. At the same time, PRP downregulates enzymes such as MMP-1 (mean, 0.16; 95\% CI, -0.007 to 0.33 ; $\mathrm{p}=0.029$ ), MMP-3 (mean, 0.01; 95\% CI, 0.0007-0.02; $\mathrm{p}=0.029$ ), and TIMP-1 (mean, 0.4; 95\% CI, 0.0-0.5; $\mathrm{p}=0.019)$. The expression of COL1A1 and COL $3 \mathrm{~A} 1$ was downregulated after PRP treatment (mean, 0.38; 95\% CI, $0.21-0.54 ; \mathrm{p}=0.029$; mean, $0.30 ; 95 \% \mathrm{CI}, 0.11-0.48$; $\mathrm{p}=0.029$, respectively). Expression of COX1 and ADAMTS5 was not detected.

PRP could appear to mitigate the inflammatory and angiogenic status of already inflamed tenocytes because its 

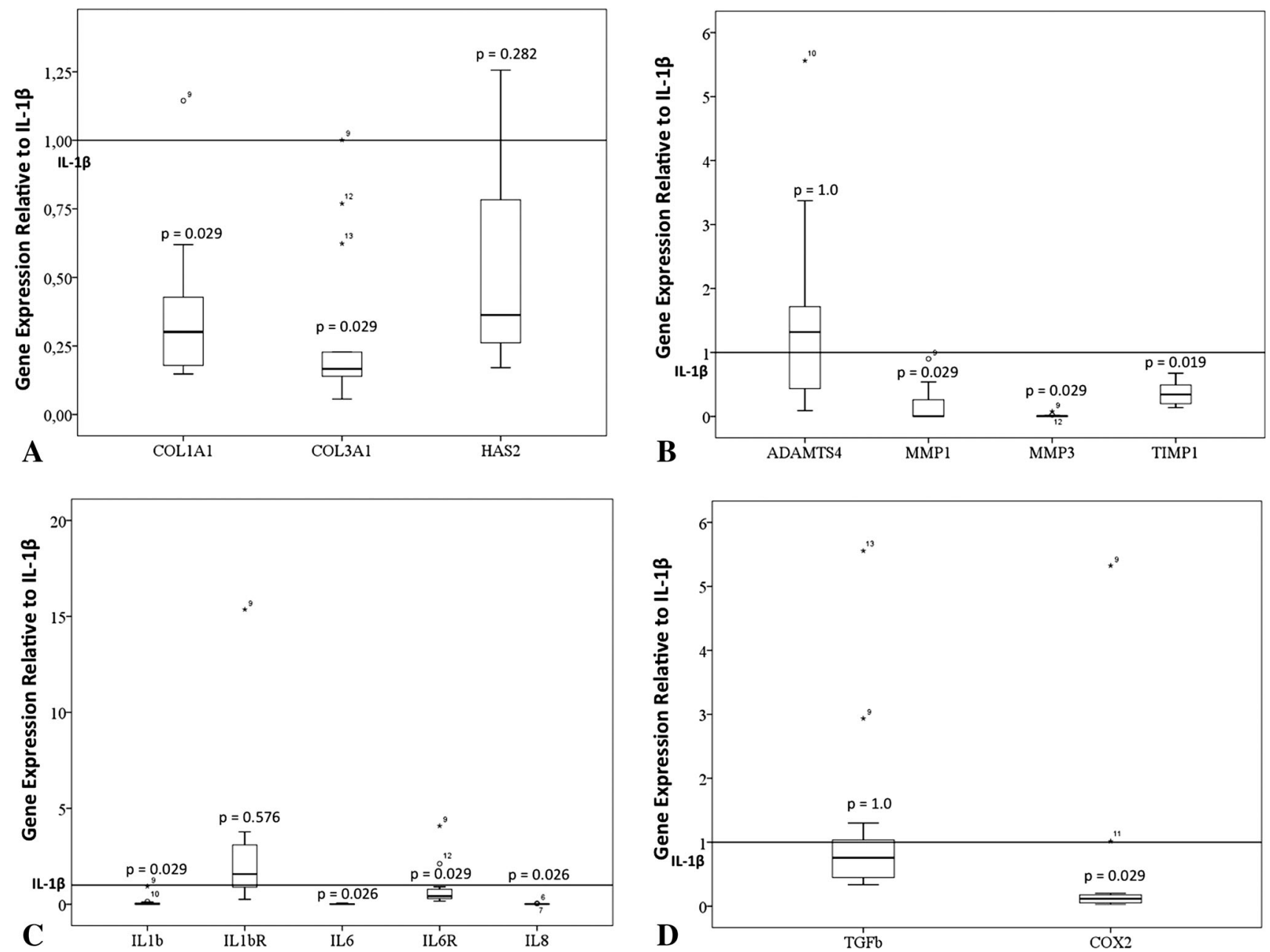

Fig. 2A-D Relative gene expression of (A-B) modulators of inflammation and (C-D) extracellular matrix proteins. Boxes illustrate the relative mRNA expression; the band inside the box is the

application resulted in modulation of the secretion of chemokines and interleukins that are upregulated in inflamed tendons cells. PRP contains a pool of interleukins, chemokines, and growth factors relevant to inflammation and angiogenesis (Table 3). Inflamed tendon cells secrete CXCL and CCL chemokines. Interleukin-6/CXCL-6 (1485 ng/10 ${ }^{6}$ cells; 95\% CI, 523-2448), IL-8/CXCL-8 (768 ng/10 cells; 95\% CI, 209-1324), and MCP-1/CCL-2 secretion $\left(475 \mathrm{ng} / 10^{6}\right.$ cells; 95\% CI, 227-722) were strongly induced in response to inflammation (Table 4). All three cytokines (IL-6/CXCL6, IL-8/CXCL8, and MCP-1/ CCL2) were reduced after treatment with PRP as shown by normalizing PRP induced secretion by the matching inflamed cells (PRP/IL-1ß): IL-6/CXCL6, 0.35 (95\% CI, 0.3-0.4; $\mathrm{p}=0.002$ ), IL-8/CXCL8, 0.55 (95\% CI, 0.5-0.7; $\mathrm{p}=0.01)$, and MCP-1/CCL2, 0.40 (95\% CI, 0.2-0.6; $\mathrm{p}=0.001$; Fig. 3). GRO-alpha/CXCL1 and RANTES/ CCL5 were also secreted in response to IL-1ß (Table 4).

median. mRNA folds of PRP-treated tendon cells are calculated relative to tendon cells subjected to inflammatory stimuli (IL-1ß).

Notwithstanding its antiinflammatory properties, PRP did not modify GRO-alpha/CXCL1 secretion (Fig. 3B) and increased RANTES/CCL5 by eightfold (95\% CI, 2-15; $\mathrm{p}<0.001$ ). Regarding modulation of selected growth factors, tendon cells showed a relatively high constitutive secretion of HGF, $35 \mathrm{ng} / 10^{6}$ cells (95\% CI, 18-52), which was reduced in the presence of IL- $1 \beta, 8.7 \mathrm{ng} / 10^{6}$ cells (95\% CI, -3 to 20). PRP treatment restored the levels of HGF secretion (increased fourfold [range, 1-47; $p=0.002]$ ) in the inflamed cells. In contrast, PRP further enhanced VEGF production (3D) twofold induced by IL-1B (95\% CI, 1.7-2.3; p < 0.001). Cytokine interactions are reflected by strong correlations between inflammatory/angiogenic proteins. Monocyte chemotactic protein-1/CCL2 showed evidence of a positive association with IL-6/ CXCL6 and IL-8/CXCL8 ( $\mathrm{R}=0.949$ and $\mathrm{R}=0.738$; $\mathrm{p}=0.001$ for both), whereas there was evidence of a negative association of MCP-1/CCL2 with HGF 
Table 2. Individual values of gene expression relative to housekeeping genes*

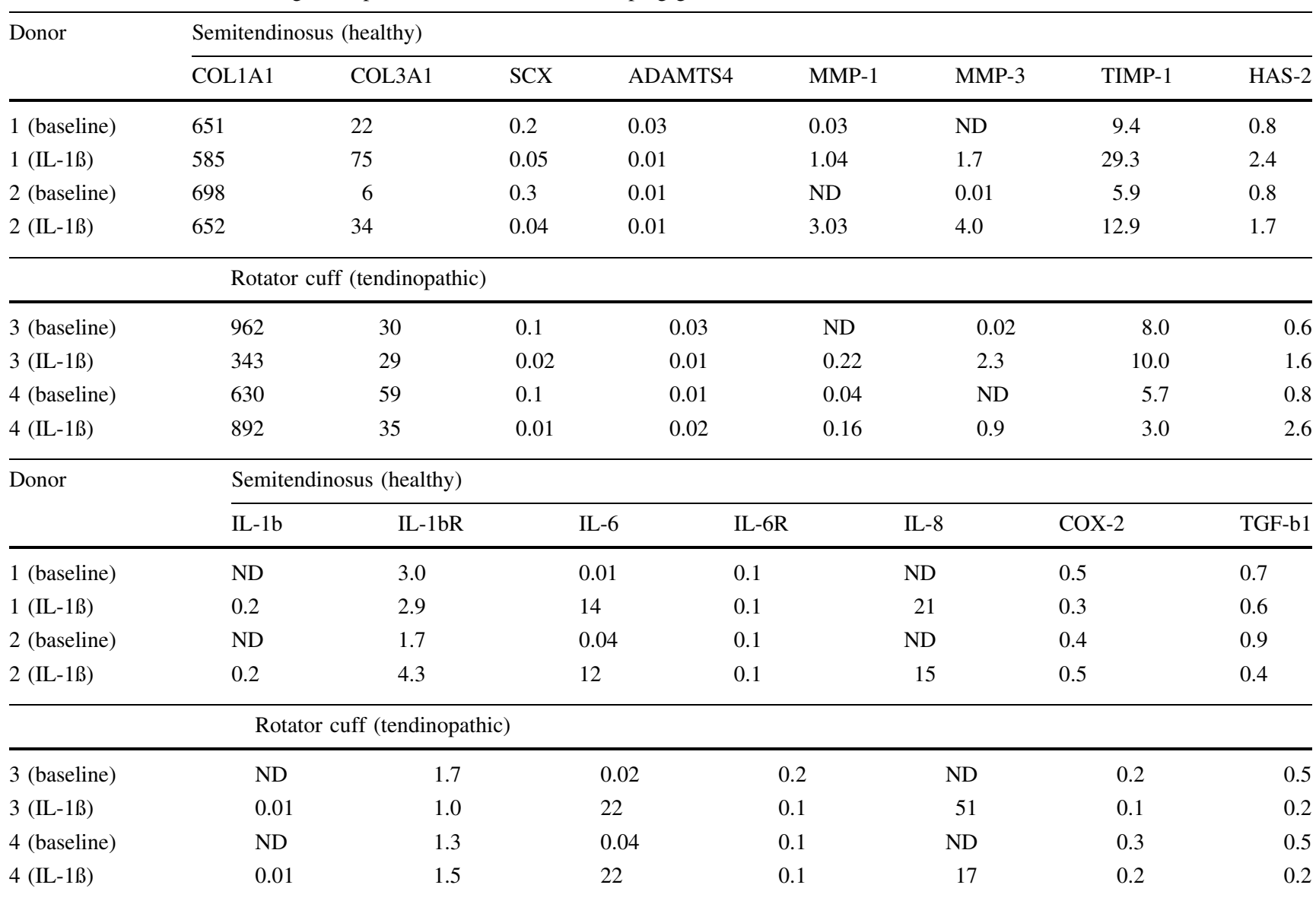

* Gene expression of extracellular matrix associated molecules and inflammatory molecules at baseline (30-hour starvation) and after 48-hour IL- $1 ß$ exposure $\left(0.1 \%\right.$ platelet-rich plasma). Gene expression data are presented as $2^{- \text {deltaCt }}=2^{-[\mathrm{Ct} \text { gene of interest-(CtGAPDH+CtTBP)/2] }}$ normalizing the expression of the genes of interest to the mean Ct of GAPDH and TBP. Mean efficiency of polymerase chain reaction is $96 \%$ (SD $=4 \%$ ), $\mathrm{CV}=4 \%$. Mean housekeeping $\mathrm{Ct}=22 \mathrm{SD}=1.6$. Housekeeping gene stability, $\mathrm{GAPDH} / \mathrm{TBP}=0.648(\mathrm{SD}=0.021)$, variation coefficient $=3 \%$. COX-1 and ADAMTS5 were not detected, $\mathrm{Ct}>30$ cycles; IL-1 $\beta=$ interleukin 1 beta; IL-1 $\beta \mathrm{R}=$ interleukin 1 beta receptor; IL$6=$ interleukin 6 ; IL-6R $=$ interleukin 6 receptor; IL-8 $=$ interleukin 8 ; TGF- $\beta=$ transforming growth factor beta1; COX-1 and COX$2=$ cytochrome $\mathrm{c}$ oxidase subunit 1 and subunit 2 ; COL1A1 = collagen type 1 alpha 1 ; COL $3 \mathrm{~A} 1=$ collagen type 3 alpha 1 ; HAS2 = hyaluronan synthase 2; ADAMTS4 and ADAMTS5 = ADAM metallopeptidase with thrombospondin type 1 motif, 4 and motif, 5; MMP1 = matrix metallopeptidase 1 (interstitial collagenase); MMP-3 = matrix metallopeptidase 3 (stromelysin 1 , progelatinase); TIMP-1 = TIMP metallopeptidase inhibitor 1; GAPDH = glyceraldehyde-3-phosphate dehydrogenase; TBP = TATA box binding protein; ND = not detected; $\mathrm{CV}=$ coefficient of variation

$(\mathrm{R}=-0.406 ; \mathrm{p}=0.049)$. Vascular endothelial growth factor showed evidence of a positive association with RANTES/CCL5 and GRO-alpha/CXCL1(R = 0.682; $\mathrm{p}<0.001$ and $\mathrm{R}=0.559 ; \mathrm{p}=0.005$, respectively). In contrast, there was evidence of a negative association between VEGF and PGE2 ( $\mathrm{R}=-0.567 ; \mathrm{p}=0.004)$. IL-6/ CXCL6 showed evidence of an association with IL-8/ CXCL8 ( $\mathrm{R}=0.734 ; \mathrm{p}<0.001)$, and IL-8/CXCL8 also showed evidence of a positive association with GRO-alpha/ CXCL1 $(\mathrm{R}=0.454 ; \mathrm{p}=0.026)$ and a negative association with HGF $(\mathrm{R}=-0.628 ; \mathrm{p}=0.001)$. RANTES/CCL5 and GRO-alpha/CXCL1 also showed evidence of a positive association $(\mathrm{R}=0.566 ; \mathrm{p}=0.004)$ and a negative association with PGE2 ( $\mathrm{R}=-0.559 ; \mathrm{p}=0.005)$.

PRP appears to modulate similarly inflammatory/ angiogenic proteins in healthy and tendinopathic cells once intercell variability is reduced by normalizing PRP-induced protein secretion by the specific cell donor-inflamed cells (Fig. 4). Nevertheless, PRP induced a greater increase in RANTES in tendinopathic cells 10-fold (95\% CI, 4-17) subjected to inflammatory stimuli compared with healthy cells, a 2.3-fold increase (95\% CI, 2-3; p = 0.005). Also, PRP induced a greater increase in HGF in tendinopathic cells (21-fold; 95\% CI, 0.2-42) subjected to inflammatory 
Table 3. Concentration of angiogenic/inflammatory molecules in the PRP lysates from eight donors (1-4 healthy donors and 5-8 tendinopathic donors)*

\begin{tabular}{|c|c|c|c|c|c|c|c|c|c|}
\hline $\begin{array}{l}\text { PRP } \\
\text { donors }\end{array}$ & $\begin{array}{l}\text { MCP-1 } \\
(\mathrm{pg} / \mathrm{mL})\end{array}$ & $\begin{array}{l}\text { VEGF } \\
(\mathrm{pg} / \mathrm{mL})\end{array}$ & $\begin{array}{l}\text { HGF } \\
(\mathrm{pg} / \mathrm{mL})\end{array}$ & $\begin{array}{l}\text { IL-6 } \\
\text { (pg/mL) }\end{array}$ & $\begin{array}{l}\text { IL-8 } \\
(\mathrm{pg} / \mathrm{mL})\end{array}$ & $\begin{array}{l}\text { GRO- } \alpha \\
(\mathrm{pg} / \mathrm{mL})\end{array}$ & $\begin{array}{l}\text { RANTES } \\
\text { (ng/mL) }\end{array}$ & $\begin{array}{l}\text { PGE-2 } \\
\text { (ng/mL) }\end{array}$ & $\begin{array}{l}\text { GAGs } \\
(\mu \mathrm{g} / \mathrm{mL})\end{array}$ \\
\hline 1 & 230 & 150 & 430 & 950 & ND & 300 & 24. & 27 & 32 \\
\hline 2 & 1440 & 120 & 870 & 4870 & 550 & 2370 & 23 & 11 & 34 \\
\hline 3 & 100 & 240 & 520 & 1030 & ND & 1560 & 22 & 11 & 103 \\
\hline 4 & 910 & 140 & 480 & 6870 & ND & 410 & 23 & 26 & 101 \\
\hline 5 & 880 & 130 & 730 & 1030 & ND & 510 & 22 & 16 & 101 \\
\hline 6 & 120 & 260 & 620 & 2200 & ND & 320 & 26 & 9 & 73 \\
\hline 7 & 100 & 170 & 680 & 1030 & ND & 80 & 27 & 1 & 84 \\
\hline 8 & 410 & 120 & 570 & 1700 & ND & 1650 & 24 & 20 & 52 \\
\hline
\end{tabular}

* Results are expressed as $\mathrm{pg} / \mathrm{mL}, \mathrm{ng} / \mathrm{mL}$, or $\mu \mathrm{g} / \mathrm{mL}$ of technical duplicates; PRP = platelet-rich plasma; MCP- $1=$ monocyte chemoattractant protein 1; VEGF = vascular endothelial growth factor; HGF = hepatocyte growth factor; IL = interleukin; GRO- $\alpha=$ growth-regulated alpha protein; RANTES $=$ regulated on activation, normal $\mathrm{T}$ expressed and secreted; PGE2 = prostaglandin 2; GAGs = glycosiaminoglycans; $\mathrm{ND}=$ not detected.

Table 4. Protein secretion by tendon cells at baseline (30-hour starvation), after 48-hour IL-1ß exposure (0.1\% PRP), and after 72-hour plateletrich plasma treatment (10\% PRP)

\begin{tabular}{|c|c|c|c|c|c|c|c|c|c|}
\hline \multirow[t]{2}{*}{$\begin{array}{l}\text { Experimental } \\
\text { conditions }\end{array}$} & MCP-1/CCL2 & VEGF & HGF & $\begin{array}{l}\text { IL-6/ } \\
\text { CXCL6 }\end{array}$ & $\begin{array}{l}\text { IL-8/ } \\
\text { CXCL8 }\end{array}$ & $\begin{array}{l}\text { GRO- } \alpha / \\
\text { CXCL1 }\end{array}$ & $\begin{array}{l}\text { RANTES/ } \\
\text { CCL5 }\end{array}$ & PGE2 & \multirow{2}{*}{$\begin{array}{l}\text { GAGs } \\
\left(\mu \mathrm{g} / 10^{6} \text { cells }\right)\end{array}$} \\
\hline & \multicolumn{8}{|c|}{ (mean $[\mathrm{SE}] \mathrm{ng} / 10^{6}$ cells) } & \\
\hline Baseline & $4(0.8)$ & $2.2(0.5)$ & $35(5)$ & $8.7(0.8)$ & ND & $0.85(0.4)$ & $1.4(0.9)$ & $2226(458)$ & $25(7)$ \\
\hline $95 \% \mathrm{CI}$ & $1.5-6.5$ & $0.8-3.7$ & $18-52$ & $6-11$ & & -0.4 to 2.1 & -1.6 to 4.3 & $768-3684$ & $2-48$ \\
\hline IL-1ß & 475 (78) & $6(0.4)$ & 8.7 (3.7) & 1485 (302) & 768 (175) & $37(8)$ & $53(18)$ & 815 (293) & $13(4)$ \\
\hline $95 \%$ CI & $227-722$ & $5-7$ & -3.2 to 20.6 & $523-2448$ & 209-1324 & $12-61$ & -4.2 to 109 & $54-1575$ & -1.3 to 27 \\
\hline PRP & $135(22)$ & $13(0.7)$ & $37(10)$ & $524(64)$ & $414(34)$ & $25(2.6)$ & $247(25)$ & $1142(194)$ & $122(20)$ \\
\hline $95 \%$ CI & $87-183$ & $11-14$ & $15-59$ & $383-664$ & $340-488$ & $19-30$ & 190-303 & $719-1565$ & $15-59$ \\
\hline
\end{tabular}

MCP-1 = monocyte chemoattractant protein; VEGF = vascular endothelial growth factor; HGF = hepatocyte growth factor; IL-6 = interleukin 6; IL-8 = interleukin 8; GRO- $\alpha=$ growth-regulated alpha protein; RANTES = regulated on activation, normal T expressed and secreted; PGE2 = prostaglandin 2; GAGs = glycosiaminoglycans; CI = confidence interval; ND = not detected.

stimuli compared with healthy cells (threefold increase; $95 \% \mathrm{CI}, 1-5 ; \mathrm{p}=0.005)$.

However, the associated increased levels need further confirmation using controlled trials that would involve many more cell donors.

\section{Discussion}

PRP therapies are used in patients with disorders that call for tissue regeneration; such conditions vary from acute traumatic injury to chronic degenerative pathologies. Injections of PRP to treat tendinopathy have shown moderate clinical benefits, mainly pain reduction, in diverse tendons [5]. However, the biologic mechanisms behind the observed clinical effects remain relatively poorly characterized. We therefore sought to (1) explore whether PRP could modify the inflammatory and angiogenic status of already inflamed tenocytes by examining the expression of selected genes relevant to tendon biology; (2) examine the extent to which PRP can modulate the secretion of chemokines and interleukins that are upregulated in inflamed tendons; and (3) determine whether the secretion of inflammatory/angiogenic proteins in response to PRP is different between healthy and tendinopathic cells.

Our study was limited to in vitro conditions using a single-cell phenotype that expresses scleraxis but not tenomodulin; however, tenomodulin expression was evident again in three-dimensional cultures (data not shown). Nevertheless, recent data show that scleraxis and tenomodulin expression is not specific of tenocytes because it was detected in fibroblasts, chondrocytes, and osteoblasts [38]. Our study findings are not necessarily translatable to human in vivo conditions, and further research in cocultures and/or in vivo models is needed to confirm the paracrine innate immune and angiogenic mechanisms we propose. Another limitation is that our study offers a static picture of PRP actions on inflamed tendon cells, whereas 




Fig. 3A-B Secretion of inflammatory/angiogenic molecules relative to IL-1ß exposed tendon cells. (A) Tendon cells treated with PRP showed a reduction in the secretion of IL-6, IL-8, and MCP-1 but did

the interplay between cytokines in the regulation of healing is temporospatial. We expected to see the presence of IL-8/ CXCL8 and GRO-alpha/CXCL1 in the initial phases of healing, subsequently MCP1/CCL2 involved in macrophage chemotaxis, and finally, as the macrophage phase resolved, the presence of RANTES/CCL5, which is chemotactic for lymphocytes. In reality, the sequence of molecular events evidenced by our study was differenttenocytes acquired adaptive immune functional properties as exemplified by RANTES ${ }^{\text {high }}$ phenotype in parallel with innate immune functional properties (IL $8^{\text {high }}$, GROalpha ${ }^{\text {high }}$, and $\mathrm{MCP} 1^{\text {high }}$ phenotypes). One further limitation of in vitro research is adequacy of controls. We performed a longitudinal study instead of a transversal study and compared PRP treatment with the previous situation, IL-1ß-induced inflammation. Interleukin-1ß has been proposed as an initiator of tendinopathy [30] and may be an acceptable model of tendon cell inflammation; however, the issue remains controversial. In any event, persistent presence of macrophages (important sources of IL-1ß) is supported by recent data in patients with chronic tendinopathy who had been followed up for more than 4 years [19]. Ethical issues limit harvesting healthy tendon, and thus we had to use two different anatomical sources for tendon specimen, ie, semitendinosus (healthy tendon) and rotator cuff (tendinopathic tissue). The number of each kind of tissue specimen is insufficient to compare normal versus tendinopathic cells at baseline and after IL-1ß exposure; indeed, this was not the goal of the current work but provides a foundation to look into differences in a future study. To restrain cell heterogeneity, we have normalized data obtained after PRP against IL-1ß status in each specific sample. Last, despite L-PRP being the most

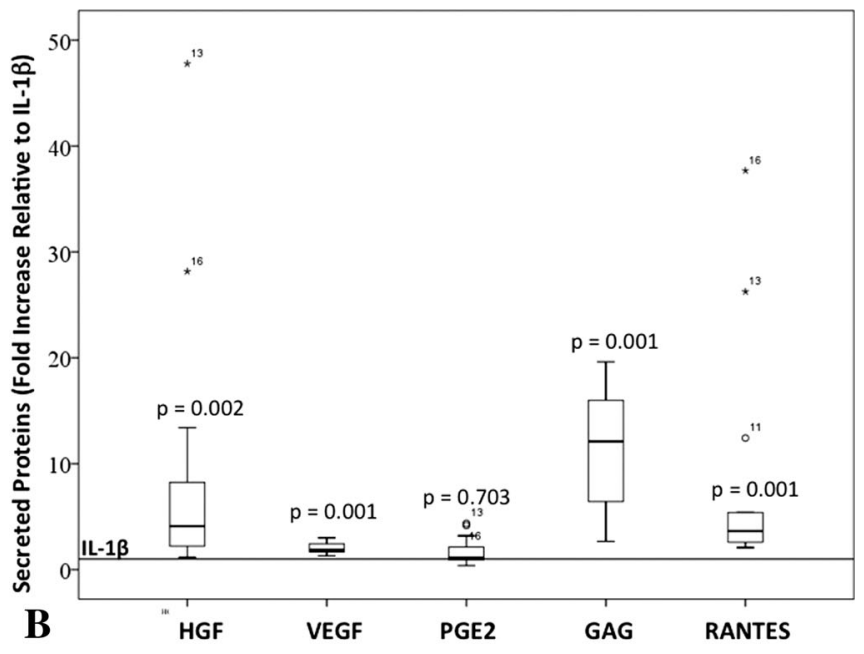

not show changes in the secretion of GRO-alpha. (B) Tendon cells treated with PRP showed increased secretion of VEGF, HGF, RANTES, and GAG but no changes in PGE2 secretion.

often used PRP in tendon treatment [7, 13, 15], we studied pure PRP to reduce experimental interdonor variability attributed to the presence of leukocytes.

The expression of some crucial inflammatory molecules including IL-6 and IL-8 was downregulated in response to PRP treatment, indicating an immunomodulatory effect of PRP in tendon cells. Inflammatory genes, including VEGF, COX-2, IL-6, IL-6R and COL1A1, are upregulated in painful and particularly in ruptured Achilles tendons in humans [21]. Remarkably, our data showed that PRP had potential to downregulate COL1A1, VEGF, COX-2, IL-6, and IL-6R. Other studies have shown that tumor necrosis factor- $\alpha$-activated tenocytes express high levels of MMP-1, IL-1ß, and IL-6 [17]. Actually, the cell-extrinsic response to stressors can involve both functional gene categories; first gene products likely involved in inflammation and tissue level adaptations such as angiogenesis and second genes that regulate the extracellular matrix compartment, ie, fibrillar collagens and remodeling enzymes (ie, MMP-1, MMP-3, ADAMTS4, and ADAMTS5) [18].

We showed some evidence supporting the concept that tendon cells are immunologically active and respond to PRP by downregulating the secretion of immunoregulatory proteins including IL-8/CXCL8, IL-6/CXCL6, and MCP-1/ CCL2 boosted by IL-1ß in tendon cells. The association of IL-6/CXCL6 and IL-8/CXCL8 with human Achilles tendon healing has been reported recently [1], but so far there is scant evidence about GRO-alpha/CXCL1 and MCP-1/CCL2 involvement in tendon biology $[8,36]$. These chemokines participate in inflammation and the production of pain caused by inflammation as well as neuropathic pain [3, 32]. Chemokine reduction may be a potential mechanism through which PRP can modulate inflammation and pain in an 

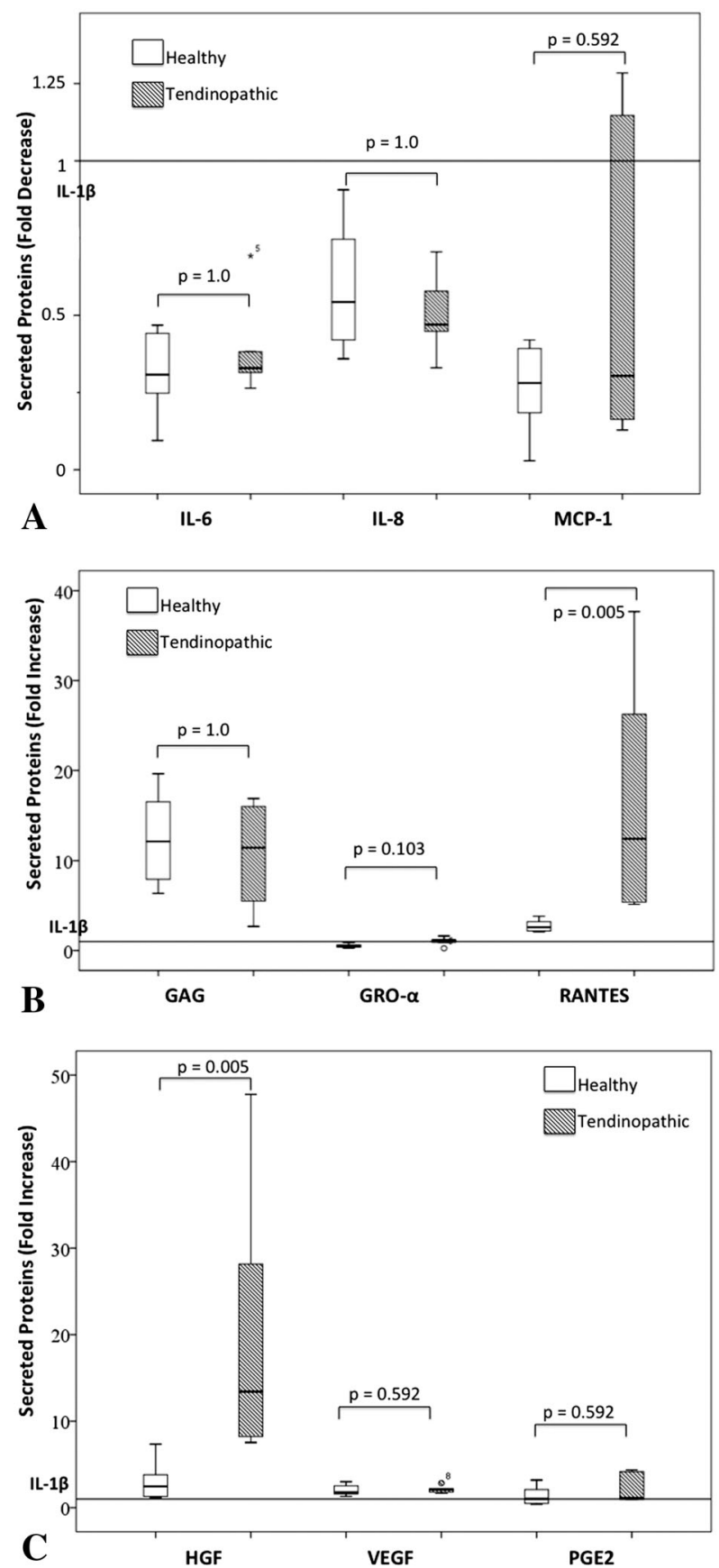

Fig. 4A-C Similarities and differences in protein secretion by healthy tendon cells and cells from tendinopathic tissue. PRP-induced changes in tendinopathic were compared with normal after normalizing PRP data against IL- $1 \beta$ status in each specific sample. Chemokine secretion is not modified by PRP (A). Differences were found in RANTES (B) and HGF secretion $(\mathbf{C})$.

inflammatory context. Actually, MCP-1/CCL2 attracts CCR2-expressing monocytes. In an experimental model for OA, Miller et al. [29] demonstrated that CCR2 signaling mediates pain in this pathology. Moreover, in a recent meta- analysis involving microarray studies, MCP-1/CCL2 was identified as one of the important pronociceptive factors in many pain models [20]. Currently, various CCR2 inhibitors are in clinical trials for treatment of pain. Although the role of MCP-1/CCL2 as an algogen in tendons is so far unexplored, MCP-1/CCL2 may interact with CCR2 receptors present in peripheral nerves in and around tendons [33]. We showed that high levels of IL-6/CXCL6 protein boosted by inflammation are reduced with use of PRP. Neutralization of IL-6/ CXCL6 can attenuate hyperalgesia [31]. Whether lowering MCP-1/CCL2 and IL-6/CXCL6 levels by means of PRP is clinically relevant in this context needs further confirmation. PRP decreases IL-8/CXCL8 but does not modify GROalpha/CXCL1, both of which are pronociceptive chemokines with similar effects regarding neutrophil chemoattraction and degranulation. However, there are many discrepancies regarding the modulatory effects of neutrophils on inflammation and pain; these are mainly attributed to the presence of different receptor subtypes and the molecular composition of the local environment [25]. For example, selective recruitment of neutrophils by GRO-alpha/CXCL1 did not induce pain in noninflamed tissue [35]. Interestingly, neutrophils participate in the endogenous control of inflammatory pain by releasing opioids acting on peripheral nerve terminals [25]. Activation of CXCR2 in neutrophils by IL-8/CXCL8 led to a release of B-endorphin and metenkephalin in vitro $[34,35]$; these chemokines can have direct actions on nociceptive neurons. Actually GRO-alpha/ CXCL1 actions are mediated by the CXCR2 receptor present in the membranes of small-diameter neurons, where it induces pronociceptive changes in excitability [40].

Comparing the response to PRP of normal and pathological cells failed to identify big differences. However, the secretion of RANTES and HGF, in response to PRP, is different in healthy and tendinopathic cells. The former is involved in leukocyte transmigration. HGF fulfills different roles; it is antiinflammatory in tendons acting through NF$\mathrm{kB}$ [40] and is chemotactic and mitogenic for endothelial cells. Whether these proteins may trigger a shift from a physiological to a pathological status is unexplored and warrants further research.

In conclusion, PRP influences tendon biology because it induces an immunomodulatory and proangiogenic phenotype consistent with healing mechanisms and pain reduction. PRP could help in recovering homeostasis under pathological conditions because it downregulates inflammatory gene expression and immunomodulatory/angiogenic protein secretion in already inflamed tendon cells. Neutralization of proinflammatory cytokines can attenuate hyperalgesia [31], but whether the reduction induced by PRP is clinically important warrants further investigation. 


\section{References}

1. Ackermann PW, Domeij-Arverud E, Leclerc P, Amoudrouz P, Nader GA. Anti-inflammatory cytokine profile in early human tendon repair. Knee Surg Sports Traumatol Arthrosc. 2013;21:1801-1806.

2. Aggarwal AK, Shashikanth VS, Marwaha N. Platelet-rich plasma prevents blood loss and pain and enhances early functional outcome after total knee arthroplasty: a prospective randomised controlled study. Int Orthop. 2014;38:387-395.

3. Alvarez P, Green PG, Levine JD. Role for monocyte chemoattractant protein-1 in the induction of chronic muscle pain in the rat. Pain. 2014;155:1161-1167.

4. Andia I, Abate M. Platelet-rich plasma: underlying biology and clinical correlates. Regen Med. 2013;8:645-658.

5. Andia I, Latorre PM, Gomez MC, Burgos-Alonso N, Abate M, Maffulli N. Platelet-rich plasma in the conservative treatment of painful tendinopathy: a systematic review and meta-analysis of controlled studies. Br Med Bull. 2014;110:99-115.

6. Andia I, Maffulli N. Platelet-rich plasma for managing pain and inflammation in osteoarthritis. Nat Rev Rheumatol. 2013;9:721730.

7. Andia I, Maffulli N. Platelet-rich plasma for muscle injury and tendinopathy. Sports Med Arthrosc. 2013;21:191-198.

8. Andia I, Rubio-Azpeitia E. Angiogenic and innate immune responses triggered by PRP in tendon cells are not modified by hyperuricemia. Muscles Ligaments Tendon J. 2014;17:292-297.

9. Andia I, Rubio-Azpeitia E, Maffulli N. Hyperuricemic PRP in tendon cells. Biomed Res Int. 2014;2014:926481.

10. Andia I, Sanchez M, Maffulli N. Tendon healing and platelet-rich plasma therapies. Expert Opin Biol Ther. 2010;10:1415-1426.

11. Anitua E, Andia I, Sanchez M, Azofra J, del Mar Zalduendo M, de la Fuente M, Nurden P, Nurden AT. Autologous preparations rich in growth factors promote proliferation and induce VEGF and HGF production by human tendon cells in culture. J Orthop Res. 2005;23:281-286.

12. Anitua E, Sanchez M, Nurden AT, Zalduendo M, de la Fuente M, Orive G, Azofra J, Andia I. Autologous fibrin matrices: a potential source of biological mediators that modulate tendon cell activities. J Biomed Mater Res A. 2006;77:285-293.

13. Bosch G, Moleman M, Barneveld A, van Weeren PR, van Schie HT. The effect of platelet-rich plasma on the neovascularization of surgically created equine superficial digital flexor tendon lesions. Scand J Med Sci Sports. 2011;21:554-561.

14. Chang KV, Hung CY, Aliwarga F, Wang TG, Han DS, Chen WS. Comparative effectiveness of platelet-rich plasma injections for treating knee joint cartilage degenerative pathology: a systematic review and meta-analysis. Arch Phys Med Rehabil. 2014;95:562575.

15. DohanEhrenfest DM, Andia I, Zumstein MA, Zhang CQ, Pinto NR, Bielecki T. Classification of platelet concentrates (plateletrich plasma-PRP, platelet-rich fibrin-PRF) for topical and infiltrative use in orthopedic and sports medicine: current consensus, clinical implications and perspectives. Muscles Ligaments Tendons J. 2014;4:3-9.

16. Guadilla J, Fiz N, Andia I, Sánchez M. Arthroscopic management and platelet-rich plasma therapy for avascular necrosis of the hip. Knee Surg Sports Traumatol Arthrosc. 2012;20:393-398.

17. John T, Lodka D, Kohl B, Ertel W, Jammrath J, Conrad C, Stoll C, Busch C, Schulze-Tanzil G. Effect of pro-inflammatory and immunoregulatory cytokines on human tenocytes. J Orthop Res. 2010;28:1071-1077.

18. Kjaer M, Bayer ML, Eliasson P, Heinemeier KM. What is the impact of inflammation on the critical interplay between mechanical signaling and biochemical changes in tendon matrix? $J$ Appl Physiol. 2013;115:879-883.
19. Kragsnaes MS, Fredberg U, Stribolt K, Kjaer SG, Bendix K, Ellingsen T. Stereological quantification of immune-competent cells in baseline biopsy specimens from Achilles tendons: results from patients with chronic tendinopathy followed for more than 4 years. Am J Sports Med. 2014;42:2435-2445.

20. LaCroix-Fralish ML, Austin JS, Zheng FY, Levitin DJ, Mogil JS. Patterns of pain: meta-analysis of microarray studies of pain. Pain. 2011;152:1888-1898.

21. Legerlotz K, Jones ER, Screen HR, Riley GP. Increased expression of IL-6 family members in tendon pathology. Rheumatology (Oxford). 2012;51:1161-1165.

22. Lin TW, Cardenas L, Glaser DL, Soslowsky LJ. Tendon healing in interleukin-4 and interleukin-6 knockout mice. $J$ Biomech. 2006;39:61-69.

23. Lyras D, Kazakos K, Verettas D, Polychronidis A, Simopoulos C, Botaitis S, Agrogiannis G, Kokka A, Patsouris E. Immunohistochemical study of angiogenesis after local administration of platelet-rich plasma in a patellar tendon defect. Int Orthop. 2010;34:143-148.

24. Lyras DN, Kazakos K, Verettas D, Polychronidis A, Tryfonidis M, Botaitis S, Agrogiannis G, Simopoulos C, Kokka A, Patsouris E. The influence of platelet-rich plasma on angiogenesis during the early phase of tendon healing. Foot Ankle Int. 2009;30:11011106.

25. Machelska H. Targeting of opioid producing leukocytes for pain control. Neuropeptides. 2007;41:355-363.

26. Manning CN, Havlioglu N, Knutsen E, Sakiyama-Elbert SE, Silva MJ, Thomopoulos S, Gelberman RH. The early inflammatory response after flexor tendon healing: a gene expression and histological analysis. J Orthop Res. 2014;32:645-652.

27. Martin JI, Merino J, Areizaga LM, Gomez-Fernandez MC, Burgos-Alonso N, Andia I. Platelet-rich plasma (PRP) in chronic epicondylitis: study protocol for a randomized controlled trial. Trials. 2013;14-410.

28. Martins-Green M, Petreaca M, Wang L. Chemokines and their receptors are key players in the orchestra that regulates wound healing. Adv Wound Care. 2013;2:327-347.

29. Miller RE, Tran PB, Das R, Ghoreishi-Haack N, Ren D, Miller RJ, Malfait AM. CCR2 chemokine receptor signaling mediates pain in experimental osteoarthritis. Proc Natl Acad Sci U S A. 2012;109:20602-20607.

30. Mobasheri A, Shakibaei M. Is tendinitis an inflammatory disease initiated and driven by pro-inflammatory cytokines such as IL1b? Histol Histopathol. 2013;28:955-964.

31. Oka Y1, Ibuki T, Matsumura K, Namba M, Yamazaki Y, Poole S, Tanaka Y, Kobayashi S. Interleukin-6 is a candidate molecule that transmits inflammatory information to the CNS. Neuroscience. 2007;145:530-538.

32. Pflücke D, Hackel D, Mousa SA, Partheil A, Neumann A, Brack A, Rittner HL. The molecular link between C-C-chemokine ligand 2-induced leukocyte recruitment and hyperalgesia. J Pain. 2013;14:897-910.

33. Ren K, Dubner R. Interactions between the immune and nervous system in pain. Nat Med. 2010;16:1267-1276.

34. Rittner HL, Brack A, Stein C. Pain and the immune system. Br J Anaesth. 2008;101:40-44.

35. Rittner HL, Labuz D, Schaefer M, Mousa SA, Schulz S, Schäfer M, Stein C, Brack A. Pain control by CXCR2 ligands through $\mathrm{Ca} 2+$-regulated release of opioid peptides from polymorphonuclear cells. FASEB J. 2006;20:2627-2629.

36. Stålman A, Bring D, Ackermann PW. Chemokine expression of CCL2, CCL3, CCL5 and CXCL10 during early inflammatory tendon healing precedes nerve regeneration: an immunohistochemical study in the rat. Knee Surg Sports Traumatol Arthrosc. 2014 May 9 [Epub ahead of print]. 
37. Svensson CI. Interleukin-6: a local pain trigger? Arthritis Res Ther. 2010;12:145.

38. Wagenhäuser MU, Pietschmann MF, Sievers B, Docheva D, Schieker M, Jansson V, Müller PE. Collagen type I and decorin expression in tenocytes depend on the cell isolation method. BMC Musculoskelet Disord. 2012;13:140.

39. Wang JG, Strong JA, Xie W, Yang RH, Coyle DE, Wick DM, Dorsey ED, Zhang JM. The chemokine CXCL1/growth related oncogene increases sodium currents and neuronal excitability in small diameter sensory neurons. Mol Pain. 2008;4:38.

40. Zhang H, Boyette-Davis JA, Kosturakis AK, Li Y, Yoon SY, Walters ET, Dougherty PM. Induction of monocyte chemoattractant protein-1 (MCP-1) and its receptor CCR2 in primary sensory neurons contributes to paclitaxel-induced peripheral neuropathy. J Pain. 2013;14:1031-1044. 